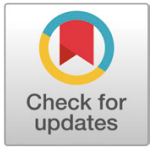

Received: Mar 16, 2020

Revised: Mar 23, 2020

Accepted: Mar 23, 2020

*Corresponding author

Changsu Kong

Department of Animal Science,

Kyungpook National University,

Sangju 37224, Korea.

Tel: +82-54-530-1225

E-mail: changsukong@knu.ac.kr

Copyright $(02020$ Korean Society of Animal Sciences and Technology.

This is an Open Access article distributed under the terms of the Creative Commons Attribution Non-Commercial License (http:// creativecommons.org/licenses/by$\mathrm{nc} / 4.0 /$ ) which permits unrestricted non-commercial use, distribution, and reproduction in any medium, provided the original work is properly cited.

ORCID

Byoung-Ki An

https://orcid.org/0000-0002-3158-2491

Su Hyun An

https://orcid.org/0000-0001-6236-6815

Han-Seul Jeong

https://orcid.org/0000-0001-5548-336X

Kwan-Eung Kim

https://orcid.org/0000-0002-8392-9864

Eun Jip Kim

https://orcid.org/0000-0002-6243-0407

Sang-Rak Lee

https://orcid.org/0000-0002-8905-0770

Changsu Kong

https://orcid.org/0000-0002-3876-6488

\section{Evaluation of energy and amino acids of brown rice and its effects on laying performance and egg quality of layers}

\author{
Byoung-Ki An', Su Hyun An², Han-Seul Jeong ${ }^{1}$, Kwan-Eung Kim³ , Eun Jip Kim, \\ Sang-Rak Lee ${ }^{1}$ and Changsu Kong ${ }^{2,5 *}$ \\ ${ }^{1}$ Department of Animal Science and Technology, Konkuk University, Seoul 05029, Korea \\ ${ }^{2}$ Department of Animal Science and Biotechnology, Kyungpook National University, Sangju 37224, Korea \\ ${ }^{3} R \& D$ Center, Nonghyup Feed, Seoul 05398, Korea \\ ${ }^{4}$ Division of Animal Husbandry, Yonam College, Cheonan 31005, Korea \\ ${ }^{5}$ Department of Animal Science, Kyungpook National University, Sangju 37224, Korea
}

\section{Abstract}

Two experiments were conducted to determine apparent metabolizable energy (AME), nitrogen-corrected AME (AMEn), and ileal digestible amino acid (AA) content of brown rice (BR) and to investigate the effect of dietary supplementation of $B R$ on laying performance and egg quality of laying hens. In Exp. 1, 72 Hy-line Brown layers (49-week-old) were allocated to two treatments using a completely randomized block design, and each treatment included six cages per treatment and six hens per cage. A semi-purified diet was formulated to include BR as the sole source of $\mathrm{AA}$ and energy and an $\mathrm{N}$-free diet was used to determine basal endogenous loss of AA. The hens were fed a commercial layer diet for adaptation to the experimental environment and diet for 7 days from $\mathrm{d} 0$, and then fed experimental diets for 5 days from d 7. Excreta were collected from d 10 to 11 and ileal digesta were collected on d 12. On a dry matter (DM) basis, the AME and AMEn of BR was determined at 3,773 and $3,729 \mathrm{kcal} / \mathrm{kg}$, respectively. The apparent ileal digestibility (AID) of BR ranged from $32.7 \%$ for Thr to $73.7 \%$ for Arg. The range of the standardized ileal digestibility (SID) value was between $79.4 \%$ for Met and $96.6 \%$ for Lys. In Exp. 2, $252 \mathrm{Hy}$-line Brown layers (44-week-old) were divided into four groups, comprising seven replicates of nine birds each and assigned to four experimental diets containing 0 (Control), $5 \%, 10 \%$, or $15 \%$ BR for 5 weeks. The BR-containing diets were formulated to be equal in the content of AMEn and digestible AA to those of the diet without BR. No significant differences were observed in laying performances. Egg quality and blood profiles were not linearly or quadratically affected by dietary treatments. These results suggest that up to $15 \%$ BR can be included into layer feed without any adverse effects on laying performance and egg quality, if its energy and digestible AA values are well evaluated.

Keywords: Brown rice, Apparent metabolizable energy, Standardized ileal digestible amino acids, Egg production, Laying hens 
Competing interests No potential conflict of interest relevant to this article was reported.

Funding sources

Not applicable.

Acknowledgements

Not applicable.

Availability of data and material Upon reasonable request, the datasets of this study can be available from the corresponding author.

Authors' contributions

Conceptualization: An BK, Kim KE, Kim EJ, Lee SR, Kong C.

Data curation: An SH, Jeong HS.

Formal analysis: $\mathrm{An} \mathrm{SH}$, Jeong HS

Methodology: An SH, Jeong HS.

Software: An SH, Jeong HS.

Validation: An SH, Jeong HS.

Investigation: An SH, Jeong HS.

Writing - original draft: An BK, Kong C.

Writing - review \& editing: An BK, An SH,

Kong $\mathrm{C}$.

Ethics approval and consent to participate The Institutional Animal Care and Use Committee at Konkuk University approved the techniques and procedures involved in the animal care and handling (KU18136).

\section{INTRODUCTION}

Rice (Oryza sativa L.) is a staple food for humans and is produced in many countries worldwide. In Korea, rice production is increasing, whereas rice consumption per capita is decreasing, resulting in an increase in rice stockpiles. Rice stored for a long time is rejected for human consumption because of its low eating quality, and is thus being supplied for feedstuff at prices competitive to those of cereal grains. As a potential feedstuff, brown rice (BR) has been used in feeding trials in poultry diets and has demonstrated similar efficiency to corn grain in egg production or growth [1,2]. Sittiya et al. [3] also reported that laying performance and egg qualities, except for yolk color, were not influenced by dietary treatment in which corn was replaced with rice at different levels. However, it has been noted that $\mathrm{BR}$ varieties show high variability in feeding value, especially in true metabolizable energy [4].

It is well known that information on the availability of energy and amino acids (AA) in newly applied feedstuff is necessary for more accurate diet formulation and a control on diet quality [5]. Larbier et al. [6] also suggested that diet formulation using vegetable protein feedstuffs on an available AA basis is more advantageous than formulation on a total AA basis. Therefore, BR that has been stored long-term should be evaluated as a potential feed ingredient for layers before use. This study was conducted to determine metabolizable energy and digestible amino acids in BR and to investigate its optimal feeding level for commercial layers.

\section{Materials and Methods}

Ingredient, diets, animals, and management

The BR (Oryza sativa) used in the present experiment was obtained from Nonghyup Feed, Seoul, Republic of Korea. The BR sample was stored for three years after harvest before being used in the experiment.

In experiment 1, a metabolism study with 49-week-old Hy-Line Brown layers was conducted for 5 days to determine the utilization of AA and energy in the BR used for the feeding trial. A semi-purified diet containing $\mathrm{BR}$ as the sole $\mathrm{AA}$ and energy source was used to determine the apparent metabolizable energy (AME) and nitrogen-corrected AME (AMEn) as well as the apparent ileal digestibility (AID) of AA in the BR (Table 1). An N-free diet was also used to determine the basal endogenous losses (BEL) of AA for the correction of AID to standardized ileal digestibility (SID). All diets were supplied in mash form and chromic oxide was used as an index of indigestibility. On $\mathrm{d} 0$, a total of 72 hens were weighed individually and grouped into six blocks by body weight and randomly allocated to two dietary treatments in each block with six hens per cage in a completely randomized block design. The hens were fed a commercial layer diet for adaptation to the experimental environment and diet for 7 days from $\mathrm{d} 0$, and then fed experimental diets for 5 days from $\mathrm{d}$ 7. The diets and water were supplied ad libitum during the adaptation and experimental periods.

In experiment 2, a feeding trial lasting 5 weeks was conducted using $252 \mathrm{Hy}$-Line Brown layers (44-week-old). Four experimental diets were formulated to investigate optimal feeding level of $\mathrm{BR}$, and $0 \%, 5 \%, 10 \%$, and $15 \%$ of $\mathrm{BR}$ was incorporated into corn-soybean meal-based diets at the expense of corn and soybean meal (Table 2). Limestone addition increased with increasing levels of BR. The hens were housed in a caged layer house and had ad libitum access to the experimental diets and water. Hens were randomly allocated to the four experimental diets with seven replicates in a completely randomized design. Each replicate comprised three cages with three birds per wire cage $(48 \times 48 \mathrm{~cm})$. 
Table 1. Composition of ingredients in the diets used in Experiment 1; as-fed basis

\begin{tabular}{lcc}
\hline \multicolumn{1}{c}{ Item } & \multicolumn{2}{c}{ Experimental diets } \\
\cline { 2 - 3 } & Brown rice & NFD $^{\mathbf{1}}$ \\
\hline Ingredient (\%) & 94.82 & - \\
Ground brown rice & - & 28.79 \\
Cornstarch & - & 55.00 \\
Sucrose & - & 4.00 \\
Soybean oil & 1.99 & 1.88 \\
Ground limestone & 1.79 & 2.14 \\
Monocalcium phosphate & 0.50 & 0.50 \\
Chromic oxide & 0.40 & - \\
Sodium chloride & 0.50 & 1.00 \\
Vitamin-mineral premix ${ }^{2)}$ & - & 5.00 \\
Cellulose & - & 0.25 \\
Choline chloride & - & 0.09 \\
Magnesium oxide & - & 0.30 \\
Potassium carbonate & - & 0.30 \\
Potassium chloride & - & 0.75 \\
Sodium bicarbonate & 100 & 100 \\
Total & &
\end{tabular}

${ }^{11}$ Nitrogen-free diet (NFD) contained a calculated electrolyte balance of $114.8 \mathrm{mEq}$.

${ }^{2)}$ Provided per kg of diet: vitamin $\mathrm{A}, 80,000 \mathrm{IU}$; vitamin $\mathrm{D}_{3}, 15,000 \mathrm{IU}$; vitamin $\mathrm{E}, 40 \mathrm{IU}$; vitamin $\mathrm{K}_{3}, 6.6 \mathrm{mg}$; thiamine nitrate, 4.85 $\mathrm{mg}$; riboflavin, $25 \mathrm{mg}$; pyridoxine hydrochloride, $10 \mathrm{mg}$; vitamin $\mathrm{B}_{12}, 60 \mathrm{mg}$; nicotinic acid, $100 \mathrm{mg}$; calcium pantothenate, 40 $\mathrm{mg}$; folic acid, $3 \mathrm{mg}$; choline chloride, 1,750 mg; Mn, $600 \mathrm{mg}$ as manganese sulfate; $\mathrm{Zn}, 450 \mathrm{mg}$ as zinc sulfate; $\mathrm{Fe}, 200 \mathrm{mg}$ as ferrous sulfate and ferric oxide; $\mathrm{Cu}, 25 \mathrm{mg}$ as cupric sulfate; I, $12.5 \mathrm{mg}$ as calcium iodate; $\mathrm{Co}, 5 \mathrm{mg}$ as cobaltous carbonate; and $\mathrm{Se}, 2.5 \mathrm{mg}$ as sodium selenite.

For both experiments 1 and 2, the hens were reared under standard conditions of temperature $\left(23^{\circ} \mathrm{C} \pm 3^{\circ} \mathrm{C}\right)$, humidity $(60 \%)$, and artificial lighting $(16 \mathrm{~L} / 8 \mathrm{D})$. Vitamins and trace minerals in all diets were included to meet or exceed nutrient requirement estimates [7].

\section{Excreta and digesta collection and chemical analyses}

In experiment 1 , excreta collection were performed twice a day from d 10 to 11 . On d 12, all the birds were killed by $\mathrm{CO}_{2}$ asphyxiation, and the ileal digesta samples were collected from the distal ileum through flushing with distilled water. The collected ileal samples were pooled by each cage. The collected excreta and ileal digesta samples were stored in a freezer at $-20^{\circ} \mathrm{C}$ until further analyses. At the end of the experiment, excreta and ileal digesta samples were thawed and the excreta samples were dried in a forced-air oven at $55^{\circ} \mathrm{C}$ for $96 \mathrm{~h}$ and all ileal digesta samples were freezedried.

Gross energy (GE) of ingredient, diets, and excreta samples was determined in an isoperibol bomb calorimeter (Parr 6200, Parr Instruments, Moline, IL, USA). The experimental ingredient, diets, excreta, and ileal digesta samples were analyzed for crude protein (CP; AOAC [8]; method 990.03). The content of AA in the experimental ingredient, diets, and ileal digesta samples was determined (AOAC [8]; method 994.12; method 988.15). Chromium concentrations in the diets, excreta, and ileal digesta were analyzed according to the procedure described by Fenton and Fenton [9].

\section{Egg production}

In experiment 2, egg production and egg weight were determined daily. Except for abnormal eggs, 


\begin{tabular}{|c|c|c|c|c|}
\hline \multirow{2}{*}{ Ingredients (\%) } & \multicolumn{4}{|c|}{ Brown rice $(\%)$} \\
\hline & 0 & 5 & 10 & 15 \\
\hline Corn & 53.55 & 48.75 & 43.85 & 38.85 \\
\hline Wheat & 5.00 & 5.00 & 5.00 & 5.00 \\
\hline Brown rice & 0.00 & 5.00 & 10.00 & 15.00 \\
\hline Soybean meal & 15.70 & 15.50 & 15.30 & 15.10 \\
\hline Canola meal & 4.00 & 4.00 & 4.00 & 4.00 \\
\hline DDGS & 5.00 & 5.00 & 5.00 & 5.00 \\
\hline Corn gluten meal & 4.00 & 4.00 & 4.00 & 4.00 \\
\hline Tallow & 1.30 & 1.20 & 1.20 & 1.30 \\
\hline Lysine $\mathrm{HCl}, 78 \%$ & 0.20 & 0.20 & 0.20 & 0.20 \\
\hline DL-Met, 98\% & 0.10 & 0.10 & 0.10 & 0.10 \\
\hline Monocalcium phosphate & 0.60 & 0.60 & 0.60 & 0.60 \\
\hline Limestone & 10.00 & 10.10 & 10.20 & 10.30 \\
\hline Salt & 0.30 & 0.30 & 0.30 & 0.30 \\
\hline Vitamin mixture $^{1)}$ & 0.10 & 0.10 & 0.10 & 0.10 \\
\hline Mineral mixture ${ }^{2)}$ & 0.10 & 0.10 & 0.10 & 0.10 \\
\hline Phytase & 0.05 & 0.05 & 0.05 & 0.05 \\
\hline Total & 100.0 & 100.0 & 100.0 & 100.0 \\
\hline \multicolumn{5}{|l|}{ Calculated nutrient content } \\
\hline AMEn (kcal/kg) & 2,700 & 2,700 & 2,700 & 2,700 \\
\hline Crude protein & 17.0 & 17.0 & 17.0 & 17.0 \\
\hline $\mathrm{Ca}$ & 4.1 & 4.1 & 4.1 & 4.1 \\
\hline Non phytate $\mathrm{P}$ & 0.4 & 0.4 & 0.4 & 0.4 \\
\hline \multicolumn{5}{|l|}{ SID amino acid } \\
\hline Arg & 0.88 & 0.88 & 0.88 & 0.88 \\
\hline His & 0.40 & 0.39 & 0.38 & 0.38 \\
\hline lle & 0.62 & 0.61 & 0.60 & 0.59 \\
\hline Leu & 1.54 & 1.52 & 1.49 & 1.46 \\
\hline Lys & 0.65 & 0.65 & 0.64 & 0.63 \\
\hline Met & 0.28 & 0.28 & 0.28 & 0.27 \\
\hline Cys & 0.25 & 0.25 & 0.25 & 0.24 \\
\hline Phe & 0.77 & 0.76 & 0.75 & 0.74 \\
\hline Thr & 0.57 & 0.56 & 0.55 & 0.54 \\
\hline Trp & 0.14 & 0.14 & 0.13 & 0.13 \\
\hline Val & 0.70 & 0.69 & 0.69 & 0.68 \\
\hline
\end{tabular}

${ }^{1}$ Vitamin mixture provided following nutrients per $\mathrm{kg}$ of diet: vitamin $\mathrm{A}, 40,000 \mathrm{IU}$; vitamin $\mathrm{D}_{3}, 8,000 \mathrm{IU}$; vitamin $\mathrm{E}, 10 \mathrm{IU}$; vitamin $\mathrm{K}_{3}, 4 \mathrm{mg}$; vitamin $\mathrm{B}_{1}, 4 \mathrm{mg}$; vitamin $\mathrm{B}_{2}, 12 \mathrm{mg}$; vitamin $\mathrm{B}_{6}, 6 \mathrm{mg}$; vitamin $\mathrm{B}_{12}, 0.02 \mathrm{mg}$; pantothenic acid, $20 \mathrm{mg}$; folic acid, $2 \mathrm{mg}$; nicotinic acid, $60 \mathrm{mg}$.

${ }^{2)}$ Mineral mixture provided following nutrients per kg of diet: Fe, $60 \mathrm{mg} ; \mathrm{Zn}, 50 \mathrm{mg}$; Mn, $25 \mathrm{mg} ; \mathrm{Cu}, 10 \mathrm{mg} ; \mathrm{l}, 1.7 \mathrm{mg} ; \mathrm{Se}, 0.10 \mathrm{mg}$. DDGS, distiller's dried grains with solubles; AMEn, nitrogen-corrected apparent metabolizable energy; SID, standardized ileal digestible.

replicated egg weight was measured for daily average of egg weight. Egg mass was calculated by multiplying the egg weight by the egg production. At the beginning and the completion of the experiment, feed intake was measured, and average daily feed intake and egg production were corrected with mortality. 


\section{Egg quality measurements}

Egg quality was determined at 14 and $28 \mathrm{~d}$ of feeding. Five eggs from each replicate were collected, weighed and stored overnight at room temperature $\left(23^{\circ} \mathrm{C} \pm 3^{\circ} \mathrm{C}\right)$ for subsequent analyses. Albumen height was measured using the DET-6000 Egg multi-tester (Nabel, Japan). The Haugh unit calculation was performed as previously described by An et al. [10]. The breaking strength for uncracked eggs was determined using an eggshell strength tester (Nabel, Japan). Eggshell thickness without shell membrane was measured using a micrometer (Digimatic micrometer, Series 547-360, Mitutoyo,Japan). Egg yolk color was determined by comparison with the Roche yolk color fan (Hoffman-La Roche, Basel, Switzerland).

\section{Blood sampling and analysis}

At the completion of the experiment, blood samples from the jugular vein were collected from seven birds per treatment. After centrifugation at 2,000×g for $15 \mathrm{~min}$, the serum samples were stored at $-60^{\circ} \mathrm{C}$ until analysis. The activity of glutamic oxaloacetic transaminase (GOT) in sampled sera was measured using the colorimetric method using GOT assay kits (Asan Pharmaceutical, Korea) according to the manufacturer's instructions. The levels of serum total protein, globulin, and albumin were measured using an automatic blood analyzer (Labospect 008AS, Hitachi, Japan).

\section{Statistical analysis}

All the data obtained in Exp. 2 were analyzed using the GLM procedure in SAS [11]. Orthogonal polynomial contrasts were used to estimate the linear and quadratic effects of dietary BR on the responses measured. Statistical significance was accepted at $p<0.05$.

\section{RESULTS}

The analyzed chemical compositions of BR used in experiments 1 and 2 are presented in Table 3 . On an as-fed basis, the $\mathrm{CP}$ and GE content of $\mathrm{BR}$ was $8.83 \%$ and $3,854 \mathrm{kcal} / \mathrm{kg}$, respectively. The concentration of AA ranged from $0.185 \%$ for Cys to $1.457 \%$ for Glu.

\section{Experiment 1}

The data presented in Table 4 show the apparent total tract retention of GE and AMEn of the BR fed to laying hens. On a dry matter (DM) basis, the AME and AMEn of BR was determined as 3,773 and $3,729 \mathrm{kcal} / \mathrm{kg}$, respectively. Basal ileal endogenous losses of AA determined from laying hens fed an $\mathrm{N}$-free diet ranged from $334 \mathrm{mg} / \mathrm{kg}$ DMI for Met to $2,571 \mathrm{mg} / \mathrm{kg}$ DM intake (DMI) for Glu (Table 5). Table 6 shows the AID and SID of AA of BR determined at the terminal ileum of laying hens. The AID of BR ranged from 32.7\% for Thr to 73.7\% for Arg. The range of SID values was between $79.4 \%$ for Met and $96.6 \%$ for Lys.

\section{Experiment 2}

The laying performance of hens fed diets with varying BR levels is presented in Table 7. Feed intake, egg production, egg weight, and daily egg mass were not affected by increasing level of BR in the diets. The results presented in Table 8 show that increasing levels of BR did not influence any egg quality parameters. The effects of varying levels of dietary BR on the blood profiles are summarized in Table 9. The serum total protein, globulin, albumin, and GOT concentration did not change as dietary $\mathrm{BR}$ concentration increased. 
Table 3. Analyzed chemical composition of brown rice and experimental diet fed to laying hens in Experiment 1; as-fed basis

\begin{tabular}{lcc}
\hline \multicolumn{1}{c}{ Item (\%) } & Brown rice & Experimental diet \\
\hline Dry matter & 87.81 & 89.94 \\
Gross energy (kcal/kg) & 3,854 & 3,216 \\
Crude protein & 8.83 & 7.65 \\
Indispensable amino acid & & \\
Arg & 0.642 & 0.550 \\
His & 0.201 & 0.171 \\
Ile & 0.321 & 0.280 \\
Leu & 0.718 & 0.619 \\
Lys & 0.368 & 0.314 \\
Met & 0.186 & 0.157 \\
Phe & 0.448 & 0.392 \\
Thr & 0.334 & 0.294 \\
Val & 0.445 & 0.394 \\
Dispensable amino acid & & \\
Ala & 0.479 & 0.414 \\
Asp & 0.746 & 0.645 \\
Cys & 0.185 & 0.159 \\
Glu & 1.457 & 1.267 \\
Gly & 0.378 & 0.325 \\
Pro & 0.472 & 0.435 \\
Ser & 0.430 & 0.381 \\
Tyr & 0.364 & 0.344 \\
\hline
\end{tabular}

Table 4. Apparent total tract retention (ATTR) of energy in brown rice fed to laying hens, DM basis ${ }^{1)}$

\begin{tabular}{lrc}
\hline \multicolumn{1}{c}{ Item } & Mean & SD \\
\hline ATTR of GE of diet $(\%)$ & 86.0 & 2.29 \\
AME of the brown rice $(\mathrm{kcal} / \mathrm{kg})$ & 3,773 & 100.4 \\
Retained N (g/kg Intake) & 5.4 & 1.56 \\
AMEn of the brown rice $(\mathrm{kcal} / \mathrm{kg})$ & 3,729 & 90.7 \\
\hline
\end{tabular}

${ }^{11}$ Values are means of six replicate cages with three hens per cage.

$\mathrm{DM}$, dry matter; SD, standard deviation; GE, gross energy; AME, apparent metabolizable energy; AMEn, nitrogen-corrected AME.

\section{DISCUSSION}

In Exp. 1, the GE content was in agreement with the values $(3,831$ and 3,800 kcal/ $\mathrm{kg}$ on an as-fed basis) reported by Asyifah et al. [4] but was much greater than the value $(3,248 \mathrm{kcal} / \mathrm{kg}$ on an as-fed basis) reported by Kim et al. [12]. The reason for this discrepancy is unclear. In the present study, a direct method in which the experimental diet included the test ingredient as the sole source of energy, was used to determine AME and AMEn of BR [13]. To our knowledge, this is the first study evaluating the AME of BR-fed laying hens. It is difficult to directly compare the AME determined in the present study and values determined in a previous study. However, the AME of 3,773 kcal/ $\mathrm{kg} \mathrm{DM}$ is the value between the true metabolizable energy values $(3,310$ and $4,200 \mathrm{kcal} / \mathrm{kg} \mathrm{DM})$ of two BR samples measured by Asyifah et al. [4]. The difference in energy value between the two 
Table 5. lleal basal endogenous losses (BEL) of amino acid in laying hens fed a nitrogen-free diet ${ }^{1)}$

\begin{tabular}{lc}
\hline \multicolumn{1}{c}{ Item } & BEL (mg/kg dry matter intake) \\
\hline Indispensable amino acid & 1,138 \\
Arg & 492 \\
His & 957 \\
Ile & 1,735 \\
Leu & 1,125 \\
Lys & 334 \\
Met & 879 \\
Phe & 1,527 \\
Thr & 1,084 \\
Val & \\
Dispensable amino acid & 1,080 \\
Ala & 2,015 \\
Asp & 715 \\
Cys & 2,571 \\
Glu & 1,108 \\
Gly & 1,084 \\
Pro & 1,476 \\
Ser & 838 \\
Tyr & \\
\hline
\end{tabular}

${ }^{1}$ Values are means of five replicate cages with six hens per cage.

Table 6. Apparent and standardized ileal digestibility (\%) of amino acids in brown rice fed to laying hens $^{1)}$

\begin{tabular}{|c|c|c|c|c|}
\hline \multirow{2}{*}{ Item (\%) } & \multicolumn{2}{|c|}{ Apparent ileal digestibility } & \multicolumn{2}{|c|}{ Standardized ileal digestibility } \\
\hline & Mean & SD & Mean & SD \\
\hline \multicolumn{5}{|c|}{ Indispensable amino acids } \\
\hline $\operatorname{Arg}$ & 73.7 & 8.0 & 94.4 & 8.1 \\
\hline His & 62.2 & 11.9 & 91.0 & 12.2 \\
\hline lle & 53.6 & 14.2 & 87.8 & 14.7 \\
\hline Leu & 60.0 & 12.6 & 88.0 & 12.7 \\
\hline Lys & 60.9 & 12.9 & 96.6 & 14.1 \\
\hline Met & 58.1 & 15.8 & 79.4 & 13.4 \\
\hline Phe & 66.4 & 10.4 & 88.8 & 9.9 \\
\hline Thr & 32.7 & 21.1 & 84.6 & 23.3 \\
\hline Val & 61.4 & 11.7 & 89.0 & 11.7 \\
\hline \multicolumn{5}{|c|}{ Dispensable amino acids } \\
\hline Ala & 61.5 & 12.4 & 87.6 & 11.2 \\
\hline Asp & 57.1 & 13.3 & 88.4 & 13.0 \\
\hline Cys & 37.0 & 19.3 & 82.1 & 20.7 \\
\hline Glu & 68.9 & 10.0 & 89.2 & 8.4 \\
\hline Gly & 54.4 & 13.6 & 88.6 & 14.0 \\
\hline Pro & 66.4 & 10.6 & 91.3 & 11.4 \\
\hline Ser & 49.1 & 16.0 & 87.8 & 16.6 \\
\hline Tyr & 63.8 & 10.9 & 88.1 & 10.0 \\
\hline
\end{tabular}

${ }^{1)}$ Values are means of six replicate cages with six hens per cage.

$\mathrm{SD}$, standard deviation. 
Table 7. Effect of graded levels of brown rice on egg laying performance in laying hens ${ }^{1)}$

\begin{tabular}{|c|c|c|c|c|c|c|c|}
\hline \multirow{2}{*}{ Item } & \multicolumn{4}{|c|}{ Brown rice (\%) } & \multirow{2}{*}{ SEM } & \multicolumn{2}{|c|}{$p$-value } \\
\hline & 0 & 5 & 10 & 15 & & Linear & Quadratic \\
\hline Feed intake (g/bird/d) & 113.4 & 112.6 & 114.1 & 114.4 & 1.75 & 0.563 & 0.776 \\
\hline Egg production (\%) & 88.0 & 92.1 & 91.6 & 91.2 & 2.65 & 0.443 & 0.416 \\
\hline Egg weight (g/egg) & 61.9 & 61.5 & 61.7 & 61.8 & 0.52 & 0.976 & 0.654 \\
\hline Daily egg mass & 54.4 & 56.5 & 56.5 & 56.3 & 1.26 & 0.430 & 0.486 \\
\hline
\end{tabular}

${ }^{11}$ Data are least square of mean of seven replicates with three cages (three birds per cage). Mean values from the overall experimental period.

SEM, standard error of the mean

Table 8. Effect of graded levels of brown rice on egg qualities in laying hens ${ }^{1)}$

\begin{tabular}{|c|c|c|c|c|c|c|c|}
\hline \multirow{2}{*}{ Item } & \multicolumn{4}{|c|}{ Brown rice (\%) } & \multirow{2}{*}{ SEM } & \multicolumn{2}{|c|}{$p$-value } \\
\hline & 0 & 5 & 10 & 15 & & Linear & Quadratic \\
\hline Yolk color, RCF & 7.1 & 7.0 & 7.2 & 7.2 & 0.08 & 0.219 & 0.620 \\
\hline Eggshell strength $\left(\mathrm{kg} / \mathrm{cm}^{2}\right)$ & 4.9 & 4.8 & 4.9 & 4.9 & 0.11 & 0.908 & 0.411 \\
\hline Eggshell thickness, $0.01 \mathrm{~mm}$ & 38.1 & 37.1 & 37.4 & 37.6 & 0.39 & 0.420 & 0.157 \\
\hline Haugh unit & 87.3 & 87.3 & 86.8 & 86.6 & 0.95 & 0.547 & 0.895 \\
\hline
\end{tabular}

${ }^{1)}$ Data are least square of mean of seven replicates with three cages (three birds per cage). Mean values from the 2nd and 4 th week after feeding

SEM, standard error of the mean; RCF, Roche color fan.

Table 9. Effect of graded levels of brown rice on blood profiles in laying hens ${ }^{1)}$

\begin{tabular}{lrrrrrrrr}
\hline \multirow{2}{*}{ Item } & \multicolumn{9}{c}{ Brown rice (\%) } & \multirow{2}{*}{ SEM } & \multicolumn{2}{c}{$p$-value } \\
\cline { 2 - 4 } & \multicolumn{1}{c}{$\mathbf{0}$} & $\mathbf{5}$ & $\mathbf{1 0}$ & $\mathbf{1 5}$ & & Linear & Quadratic \\
\hline Total protein (g/dl) & 5.6 & 5.7 & 5.9 & 6.1 & 0.20 & & 0.083 & 0.654 \\
Globulin (g/dl) & 3.2 & 3.2 & 3.4 & 3.6 & 0.17 & 0.115 & 0.554 \\
Albumin (g/dl) & 2.4 & 2.4 & 2.5 & 2.5 & 0.05 & 0.071 & 0.891 \\
GOT (U/L) & 166.3 & 175.4 & 173.7 & 174.3 & 7.66 & 0.524 & 0.583 \\
\hline
\end{tabular}

"Data are least square of mean of seven birds per treatment.

SEM, standard error of the mean; GOT, glutamic oxaloacetic transaminase.

studies may, in part, be attributed to the method for evaluation as well as the composition of samples used in these studies. In poultry diets, grains such as corn and BR are mainly used as energy yielding ingredients. Barzegar et al. [14] determined GE and AME values of corn using 42-weekold laying hens as 3,920 (as-fed basis) and 3,791 kcal/ $\mathrm{kg}$ (DM basis), respectively. Those values were comparable with the values $(3,854 \mathrm{kcal} / \mathrm{kg}$ for GE and 3,773 $\mathrm{kcal} / \mathrm{kg}$ for AME) of BR used in the present study, which may indicate that BR has the potential to be used as an energy source in poultry diet.

Amino acids play an important role in the growth of structural and protective tissues as well as metabolic functions in animals. Although the protein content of cereal grains such as corn and BR is relatively lower than that of the protein supplements, the grain accounts for a great proportion of the mixed feed; therefore, the protein supplied by the grain is significant. Thus, evaluating protein quality such as AA bioavailability or digestibility is needed to provide the accurate amount of AA required by poultry for normal functions. It has been generally accepted that SID is a better estimate than AID for formulating poultry diets because SID corrects for BEL to accurately reflect AA needs of the birds [15]. Similar to AME data, there is no available data for digestibility of AA 
in BR for comparison with the values derived from the present study. As the BR could be used as a replacement for corn, it would be reasonable to compare BR in the present study with corn in other studies. The SID of indispensable AA in BR from the present study was slightly less than that in corn reported by Adedokun et al. [15] except for Arg, His, Lys, and Val. However, the SID of most AA, except Met, was $85 \%$ or more and the difference in average SID of total AA was only 1 percentage point ( $89 \%$ for corn vs. $88 \%$ for BR), which may indicate that BR could replace corn as an AA source.

In the present study, the differences between AID and SID were slightly great and ranged from $24.8(\mathrm{Glu})$ to 51.8 (Thr) percentage points. The reasons for the large difference between the digestibility of the two might be the combined effect of the high amount of BEL of AA as well as the low amount of AA in BR. In the present study, the BEL of AA of laying hens was greater than that obtained in the study by Adedokun et al. [16] but it was less than values reported by Adedokun et al. [17]. The reason for this is not clear, but it can be speculated that the difference might be partly attributed to the age of the hens as well as diet composition of the nitrogen-free diet $[18,19]$. There were differences in calcium, starch, and sugar levels between the present and previous studies and these might contribute to the difference in the BEL [16].

In Exp. 2, the overall laying performance was not influenced by dietary BR levels, which was consistent with findings of a previous study. Sittiya et al. [3] observed that various levels of dietary paddy rice did not affect feed intake and egg production when nutrient levels were maintained in the experimental diets. Dietary BR as a replacement for corn led to a similar laying performance as that of the control diet without $B R$, which means that $\mathrm{BR}$ can be safely used up to $15 \%$ in layer diets. The AMEn value $(3,273 \mathrm{kcal} / \mathrm{kg})$ of BR derived from Exp. 1 was considered to be appropriate because there was no difference in feed intake among treatments.

There was no significant linear or quadratic trend of dietary levels of BR affecting egg and eggshell qualities. In contrast, Sittiya et al. [3] reported that yolk color was significantly decreased with increasing levels of paddy rice (50\% or more) without affecting other egg qualities. This negative effect can be attributed to low levels of xanthophyll in rice along with the presence of other feedstuff affecting yolk color. In this study, corn gluten meal and distiller's dried grains with solubles were included at a $4 \%$ or $5 \%$ level, respectively, and there was no influence on yolk color. In addition, supplementation of BR at the $15 \%$ level did not affect yolk color.

No significant differences were found in the activity of serum GOT, or in the content of albumin, globulin, and total protein among the groups. Similar to our results, no significant effect of rice feeding was found on serum biochemical parameters of broiler chickens [20]. Blood profiles could be used as general evidence to evaluate the health status of animals. Serum GOT activity with which it is possible to diagnose liver or tissue damage, is a valuable tool to estimate the safe levels for alternative feed ingredients [21]. The levels of serum albumin and globulin are indicator for hepatocyte injury and immune response, respectively $[22,23]$ and they can also be nutritional status indicator [24]. The result for blood profiles from the present study may indicate that there are no detrimental health and nutritional impacts of BR fed to layers up to $15 \%$ in diet.

Overall, we did not find any significant effects of replacing corn with BR on egg production, egg quality, and blood profiles. These results indicate that BR can be included into layer diets up to $15 \%$ without any adverse effects, if its energy and digestible AA values are well evaluated.

\section{REFERENCES}

1. Daghir NJ. Feedstuffs used in hot regions. In: Poultry production in hot climates. Trowbridge, UK: Cromwell Press; 2008. p. 160-96. 
2. Sittiya J, Yamauchi K, Takata K. Effect of replacing corn with whole-grain paddy rice and brown rice in broiler diets on growth performance and intestinal morphology. J Anim Physiol Anim Nutr. 2016;100:381-90.

3. Sittiya J, Yamauchi K, Takata K. Effects of replacing corn with whole- grain paddy rice in laying hen diets on egg production performance.J Adv Agri Technol. 2014;1:1-4.

4. Asyifah MN, Abd-Aziz S, Phang LY, Azlian MN. Brown rice as a potential feedstuff for poultry. J Appl Poult Res. 2012;21:103-10.

5. Green S, Kiener T. Digestibilities of nitrogen and amino acids in soya-bean, sunflower, meat and rapeseed meals measured with pigs and poultry. Anim Sci. 1989;48:157-79.

6. Larbier ZM, Chagneau AM, Geraert PA. Influence of ambient temperature on true digestibility of protein and amino acids of rapeseed and soybean meals in broilers. Poult Sci. 1993;72:289-95.

7. NRC [National Research Council]. Nutrient requirements of poultry. 9th ed. Washington, DC: National Academies Press; 1994.

8. AOAC [Association of Official Analytical Chemists] International. Official methods of analysis of AOAC International. 18th ed. Washington, DC: AOAC International; 2006.

9. Fenton TW, Fenton M. An improved procedure for the determination of dietary chromic oxide in feed and feces. Can J Anim Sci. 1979;59:631-4.

10. An SH, Kim DW, An BK. Effect of dietary calcium levels on productive performance, eggshell quality and overall calcium status in aged laying hens. Asian-Australas J Ami Sci. 2016;29:1477-82.

11. SAS. User's guide. ver. 8. Cary, NC: SAS Institute; 2002.

12. Kim CH, Park SB, Kang HK. Effects of replacing corn with rice or brown rice on laying performance, egg quality, and apparent fecal digestibility of nutrient in Hy-Line Brown laying hens. Korean J Poult Sci. 2016;43:97-103.

13. Kong C, Adeola O. Evaluation of amino acid and energy utilization in feedstuff for swine and poultry diets. Asian-Australas J Amin Sci. 2014;27:917-25.

14. Barzegar S, Wu SB, Noblet J, Choct M, Swick RA. Energy efficiency and net energy prediction of feed in laying hens. Poult Sci. 2019;98:5746-58.

15. Adedokun SA, Jaynes P, Payne RL, Applegate TJ. Standardized ileal amino acid digestibility of corn, corn distillers' dried grains with solubles, wheat middlings, and bakery by-products in broilers and laying hens. Poult Sci. 2015;94:2480-7.

16. Adedokun SA, Utterback P, Parsons CM, Adeola O, Lilburn MS, Applegate TJ. Comparison of endogenous amino acid flow in broilers, laying hens and caecectomised roosters. Br Poult Sci. 2009;50:359-65.

17. Adedokun SA, Pescatore AJ, Ford MJ, Ao T, Jacob JP. Investigating the effect of dietary calcium levels on ileal endogenous amino acid losses and standardized ileal amino acid digestibility in broilers and laying hens. Poult Sci. 2018;97:131-9.

18. Kong $\mathrm{C}$, Adeola O. Ileal endogenous amino acid flow response to nitrogen-free diets with differing ratios of corn starch to dextrose in broiler chickens. Poult Sci. 2013;92:1276-82.

19. Adeola $\mathrm{O}$, Xue PC, Cowieson AJ, Ajuwon KM. Basal endogenous losses of amino acids in protein nutrition research for swine and poultry. Anim Feed Sci Technol. 2016;221:274-83.

20. Mir NA, Tyagi PK, Biswas AK, Tyagi PK, Mandal AB, Kumar F, et al. Effect of feeding broken rice and distillers dried grains with solubles in a flaxseed-based diet on the growth performance, production efficiency, carcass characteristics, sensory evaluation of meat, and serum biochemistry of broiler chickens. Turk J Vet Anim Sci. 2017;41:583-9.

21. Diaz GJ, Roldán LP, Cortéz A. Intoxication of Crotalaria pallida seeds to growing chicks. Vet 
Hum Toxicol 2003;45:187-9.

22. Baghbanzadeh A, Decuypere E. Ascites syndrome in broiler: physiological and nutritional perspectives. Avian Pathol. 2008;37:117-26.

23. Javed T, Dombrink-Kurtzman MA, Richard JL, Bennett GA, Coté LM, Buck WB. Serohematologic alterations in broiler chicks on feed amended with Fusarium proliferatum culture material on fumonisin B1 and moniliformin.J Vet Diagn Invest. 1995;7:520-6.

24. Lumeiji JT. Avian clinical biochemistry. In: Kaneko JJ, Harvey JW, Bruss ML. editors. Clinical biochemistry of domestic animals. 5th ed. London, UK: Academic Press; 1997. p. 857-83. 